\title{
Photocatalytic Degradation of Anionic Dye by Zn-substituted Layered Double Hydroxide in Aqueous Solution
}

\author{
Kazuya Morimoto ${ }^{\dagger}$, Kenji Tamura, Jinhua Ye ${ }^{*}$ and Hirohisa Yamada \\ Geomaterials Group, Environmental Remediation Materials Unit, National Institute for Materials Science (NIMS), \\ 1-1 Namiki, Tsukuba, Ibaraki 305-0044, JAPAN \\ Fax: 81-29-860-4667, e-mail: YAMADA.Hirohisa@nims.go.jp \\ *Catalytic Materials Group, Environmental Remediation Materials Unit, National Institute for Materials Science (NIMS), \\ 1-2-1 Sengen, Tsukuba, Ibaraki 305-0047, JAPAN \\ 'Present address: Mineral Resources Research Group, Institute for Geo-Resources and Environment, National Institute of \\ Advanced industrial Science and Technology (AIST), Central 7, 1-1-1 Higashi, Tsukuba, Ibaraki 305-8567, JAPAN
}

Preparation of layered double hydroxide (LDH) by substituting $\mathrm{Zn}$ in the structure was attempted to create an environmentally friendly photocatalyst with anion adsorption capacities. Zn-Al-substituted LDH with different $\mathrm{Zn} / \mathrm{Al}$ molar ratios of 2, 3, and 4 were synthesized. The behavior of each synthetic Zn-Al LDH in photo-induced degradation of an anionic dye, sulforhodamine $\mathrm{B}$, in aqueous solution was evaluated by determining the ultraviolet-visible absorption spectra under ultraviolet light irradiation. Zn-Al-substituted LDH showed photocatalytic activity toward sulforhodamine $\mathrm{B}$, and degradation of sulforhodamine B was accelerated without stabilization under ultraviolet irradiation. Furthermore, the results suggested that $\mathrm{Zn}-\mathrm{Al} \mathrm{LDH}$ with a high charge density was more effective for continuous photo-induced degradation of sulforhodamine $B$ in aqueous solution compared with $\mathrm{Zn}-\mathrm{Al} \mathrm{LDH}$ with a low layer charge. Zn-Al-substituted LDH should be useful as efficient photocatalysts for harmful organic anions.

Key words: photocatalyst, photodegradation, layered double hydroxide, anionic dye, sulforhodamine B

\section{INTRODUCTION}

Recently, photocatalytic reactions have received considerable attention as effective and sustainable techniques for purifying water contaminated with various types of contaminant ${ }^{1}$. The photocatalytic properties of various materials are well recognized. During photocatalytic reactions, especially in aqueous solution, decomposition of some contaminants is promoted after an adsorption process on the photocatalyst surface. However, some principal photocatalysts, such as $\mathrm{TiO}_{2}, \mathrm{ZnO}$, and $\mathrm{CdS}$, have poor ion-adsorption properties. If such photocatalysts were to have efficient adsorption performance, then decomposition of contaminants would be accelerated.

Layered double hydroxide (LDH) has anion adsorption properties and quite a high anion exchange capacity $^{2}$. LDH is reported in nature, and it is well known in the form of anionic clays. The general formula of LDH is $\left[M^{2+}{ }_{1-x} M^{3+}{ }_{x}(\mathrm{OH})_{2}\right]\left[A^{n-}{ }_{x / n} \cdot m \mathrm{H}_{2} \mathrm{O}\right]$, where $M^{2+}$ represents a divalent metal such as $\mathrm{Mg}, \mathrm{Mn}, \mathrm{Fe}, \mathrm{Co}, \mathrm{Ni}$, $\mathrm{Cu}$, or $\mathrm{Zn}, M^{3+}$ represents a trivalent metal such as $\mathrm{Al}$, $\mathrm{Cr}, \mathrm{Mn}, \mathrm{Fe}$, or $\mathrm{Co}, x$ is equal to the $M^{3+} /\left(M^{2+}+M^{3+}\right)$ molar fraction and generally ranges from 0.17 to 0.33 , and $A$ is the interlayer anion with a valence of $n$. The octahedral hydroxide layers of $\mathrm{LDH}$ have a positive charge attributed to an isomorphic substitution of $M^{3+}$ for $\mathrm{M}^{2+}$; therefore, anions are intercalated into the interlayers of $\mathrm{LDH}$ to maintain electroneutrality with water molecules. $\mathrm{LDH}$ is also easily synthesized in the laboratory. Because various $M^{2+}$ and $M^{3+}$ can be incorporated in the LDH structure, LDH can have multiple compositions.

LDH is currently attracting a lot of attention as an environmentally friendly material because of its innocuous composition. The anion adsorption properties of LDH have been well documented in numerous studies, and it is currently utilized for water clarification and soil remediation. It is also noted that $\mathrm{LDH}$ has catalytic abilities associated with its solid basicity ${ }^{3}$ or modifications with various polyacids ${ }^{4}$. However, the photocatalytic properties of LDH itself have not yet been fully elucidated. Patzko et $\mathrm{al}^{5}$ evaluated the photocatalytic properties of $\mathrm{Zn}-\mathrm{Al} \mathrm{LDH}$ with $\mathrm{ZnO}$ derived by calcination. Valente et al. ${ }^{6}$ and Mantilla et al. ${ }^{7}$ conducted photocatalytic degradation experiments of phenol and/or 2,4 dichlorophenoxyacetic acid by using $\mathrm{Mg}-\mathrm{Zn}-\mathrm{Al} \mathrm{LDH}$ and $\mathrm{Zn}-\mathrm{Al}-\mathrm{Fe} \mathrm{LDH}$, respectively. However, the original synthetic LDH was also calcined before the degradation experiments. These studies have therefore not revealed the photocatalytic properties of untreated LDH. Although Seftel et al. ${ }^{8}$ tested photodegradation of a methyl orange dye by an untreated $\mathrm{Zn}-\mathrm{Al} \mathrm{LDH}$, these samples included a $\mathrm{ZnO}$ phase at the synthesis stage. Therefore, the photocatalytic function of uncalcined LDH has not been clearly investigated in previous research.

Previously, we investigated the properties of synthetic $\mathrm{Zn}-\mathrm{Al} \mathrm{LDH}$ in the photo-induced catalysis of a methyl orange dye ${ }^{9}$. The results of an ultraviolet (UV) irradiation experiment indicated that $\mathrm{Zn}$-Al-substituted LDH had methyl orange photocatalytic activity. The irradiation experiment was performed with a dried 
sample of $\mathrm{Zn}-\mathrm{Al} \mathrm{LDH}$, with adsorbed methyl orange applied in a thin layer on a quartz plate.

This study focused on the photodegradation of anionic dye by synthetic Zn-Al LDH particles dispersed in aqueous solution under UV light irradiation. The aim was to examine the photocatalytic activity of uncalcined LDH.

\section{EXPERIMENTAL}

To minimize the influence of carbon dioxide, synthesis and adsorption experiments were performed under a nitrogen atmosphere and with degassed distilled water. Use of glassware was completely avoided to prevent contamination with silicate ions.

\subsection{Synthesis of Zn-Al LDH}

$\mathrm{Zn}$-Al-substituted $\mathrm{LDH}$ with different $\mathrm{Zn} / \mathrm{Al}$ molar ratios of $2\left(\mathrm{Zn}_{2}-\mathrm{Al} \mathrm{LDH}\right), 3\left(\mathrm{Zn}_{3}-\mathrm{Al} \mathrm{LDH}\right)$, or $4\left(\mathrm{Zn}_{4}-\mathrm{Al}\right.$ $\mathrm{LDH})$, and with chloride anions, was synthesized as follows. An aqueous solution of $200 \mathrm{~mL}$ containing $\mathrm{ZnCl}_{2}$ and $\mathrm{AlCl}_{3} \cdot 6 \mathrm{H}_{2} \mathrm{O}$ with a total metal ion concentration of $0.5 \mathrm{~mol} / \mathrm{L}$ and with a $\mathrm{Zn} / \mathrm{Al}$ molar ratio of 2 , 3, or 4 was continuously added to $50 \mathrm{~mL}$ of distilled water in a polypropylene reactor, with vigorous stirring, at room temperature. During co-precipitation in the reactor, the $\mathrm{pH}$ was maintained at a constant value of 8 by the simultaneous addition of $1 \mathrm{~mol} / \mathrm{L} \mathrm{NaOH}$ solution. The total volume of the resulting suspension was adjusted to $500 \mathrm{~mL}$ with distilled water. Then, the suspension was stirred for $24 \mathrm{~h}$ at room temperature to avoid the generation of a $\mathrm{ZnO}$ phase. The solid products obtained were filtered and then washed with distilled water, then dried for $48 \mathrm{~h}$ with a vacuum freeze drier.

Synthesized materials were characterized as follows. The XRD patterns of the products were determined by using a powder diffractometer (Ultima IV, Rigaku) with graphite monochromatized $\mathrm{Cu} K \alpha$ radiation $(\lambda=0.1541$ $\mathrm{nm})$ at $40 \mathrm{kV}$ and $30 \mathrm{~mA}$ in the $2^{\circ}$ to $70^{\circ}$ range with a scanning rate of $1 \% \mathrm{~min}$. The $\mathrm{Zn} / \mathrm{Al}$ molar ratios of each synthesized LDH were determined as follows. Precisely $20.0 \mathrm{mg}$ of synthesized $\mathrm{LDH}$ was melted with $\mathrm{Na}_{2} \mathrm{CO}_{3}$ and $\mathrm{H}_{3} \mathrm{BO}_{3}$ in a platinum crucible. The product was dissolved in $\mathrm{HCl}$ solution, and the solution obtained was analyzed for $\mathrm{Zn}$ and $\mathrm{Al}$ concentrations by using ICP-AES (IRIS Advantage, Nippon Jarrell-Ash).

\subsection{Adsorption of anionic dye}

Sulforhodamine B (SRB; $\mathrm{C}_{27} \mathrm{H}_{29} \mathrm{~N}_{2} \mathrm{NaO}_{7} \mathrm{~S}_{2}$ [formula weight: 580.65], Fig. 1) was used as an anionic dye adsorbate. Batch experiments for SRB adsorption onto the $\mathrm{Zn}-\mathrm{Al} \mathrm{LDH}$ were performed. SRB aqueous solution with an initial concentration of $10.0 \mu \mathrm{mol} / \mathrm{L}(\mathrm{pH}$ adjusted to 10 by addition of $0.1 \mathrm{~mol} / \mathrm{L} \mathrm{NaOH}$ ) solution was mixed with each $\mathrm{Zn}-\mathrm{Al} \mathrm{LDH}$ in a $40-\mathrm{mL}$ polypropylene centrifuge tube. The concentration of LDH solid was adjusted to $10 \mathrm{mg} / \mathrm{L}$.

Each suspension was dispersed in an ultrasonic bath for $2 \mathrm{~min}$ and then placed in a shaker for $24 \mathrm{~h}$ at room temperature. The adsorption experiments were conducted under light shielding. The suspensions were then used for the following UV light irradiation experiments.

\subsection{UV light irradiation}<smiles>CCN(CC)c1ccc2c(-c3ccc(S(=O)(=O)O)cc3S(=O)(=O)[O-])c3ccc(=[N+](CC)CC)cc-3oc2c1</smiles>

Fig. 1 Structural formula of sulforhodamine B.

The suspensions of $\mathrm{Zn}-\mathrm{Al} \mathrm{LDH}$ with adsorbed SRB molecules were transferred to a quartz cell which had a 10-mm light path. They were then irradiated under UV light from an ultrahigh pressure mercury lamp (USH-250SC, Ushio Optical Modulex) for the desired length of time ( $\leq 300 \mathrm{~min})$. The photodegradation rate of SRB was monitored with an UV-Vis spectrometer (UV-2450, Shimadzu) in the wavelength range of 400 to $700 \mathrm{~nm}$.

\section{RESULTS AND DISCUSSION}

\subsection{Synthesized Zn-Al-substituted LDH}

The XRD profiles of synthesized $\mathrm{Zn}-\mathrm{Al} \mathrm{LDH}$ were consistent with that of $\mathrm{Zn}-\mathrm{Al} \mathrm{LDH}$ including chloride ions in the interlayer ${ }^{10}$. Zn-Al-substituted LDH phases with different $\mathrm{Zn} / \mathrm{Al}$ molar ratios were successfully synthesized by the co-precipitation reaction. There were no crystalline byproducts such as $\mathrm{ZnO}$, zinc hydroxide, or aluminum hydroxide in each resultant profile. The $d_{003}$ and $d_{006}$ values of $\mathrm{Zn}_{2}-\mathrm{Al} \mathrm{LDH}$ were $0.78 \mathrm{~nm}$ and $0.39 \mathrm{~nm}$ respectively. The $d_{003}$ spacing is equivalent to the thickness of a unit layer. For the pattern obtained for $\mathrm{Zn}_{3}-\mathrm{Al} \mathrm{LDH}$, the $d_{003}$ and $d_{006}$ values were the same as those of $\mathrm{Zn}_{2}-\mathrm{Al} \mathrm{LDH}$. The profile of $\mathrm{Zn}_{4}-\mathrm{Al} \mathrm{LDH}$ had $d_{003}$ and $d_{006}$ values of $0.79 \mathrm{~nm}$ and $0.39 \mathrm{~nm}$, respectively.

The $\mathrm{Zn} / \mathrm{Al}$ molar ratios in the synthesized $\mathrm{Zn}-\mathrm{Al} \mathrm{LDH}$ solid phases were calculated to be 1.94, 2.88, and 3.77, corresponding to $\mathrm{Zn}_{2}-\mathrm{Al}, \mathrm{Zn}_{3}-\mathrm{Al}$, and $\mathrm{Zn}_{4}-\mathrm{Al} \mathrm{LDH}$, respectively. These values were approximately consistent with the compositions of mixed metal solutions prepared in LDH synthesis processes.

\subsection{Photodegradation of SRB}

The photodegradation of SRB by $\mathrm{Zn}-\mathrm{Al} \mathrm{LDH}$ suspensions transferred to a quartz cell was monitored from the UV-Vis absorption spectra (Fig. 2). Initially, aqueous solutions of SRB only and SRB with $\mathrm{Zn}-\mathrm{Al}$ LDH showed a clear absorption peak at $565 \mathrm{~nm}$ and a shoulder at about $530 \mathrm{~nm}$. The absorbances of SRB without LDH and with $\mathrm{Zn}-\mathrm{Al} \mathrm{LDH}$ were the same when the solutions were left in the dark. These result suggests that $\mathrm{Zn}-\mathrm{Al} \mathrm{LDH}$ had no intrinsic catalytic activity without UV irradiation.

In the case of SRB without LDH (Fig. 2a), the reduction in absorption spectra was obviously slow during UV irradiation. In contrast, the reductions in absorbance of SRB with each $\mathrm{Zn}-\mathrm{Al} \mathrm{LDH}$ were faster than that of SRB without LDH (Fig. 2b, 2c, and 2d). During photodegradation of SRB, the peaks attributed to 

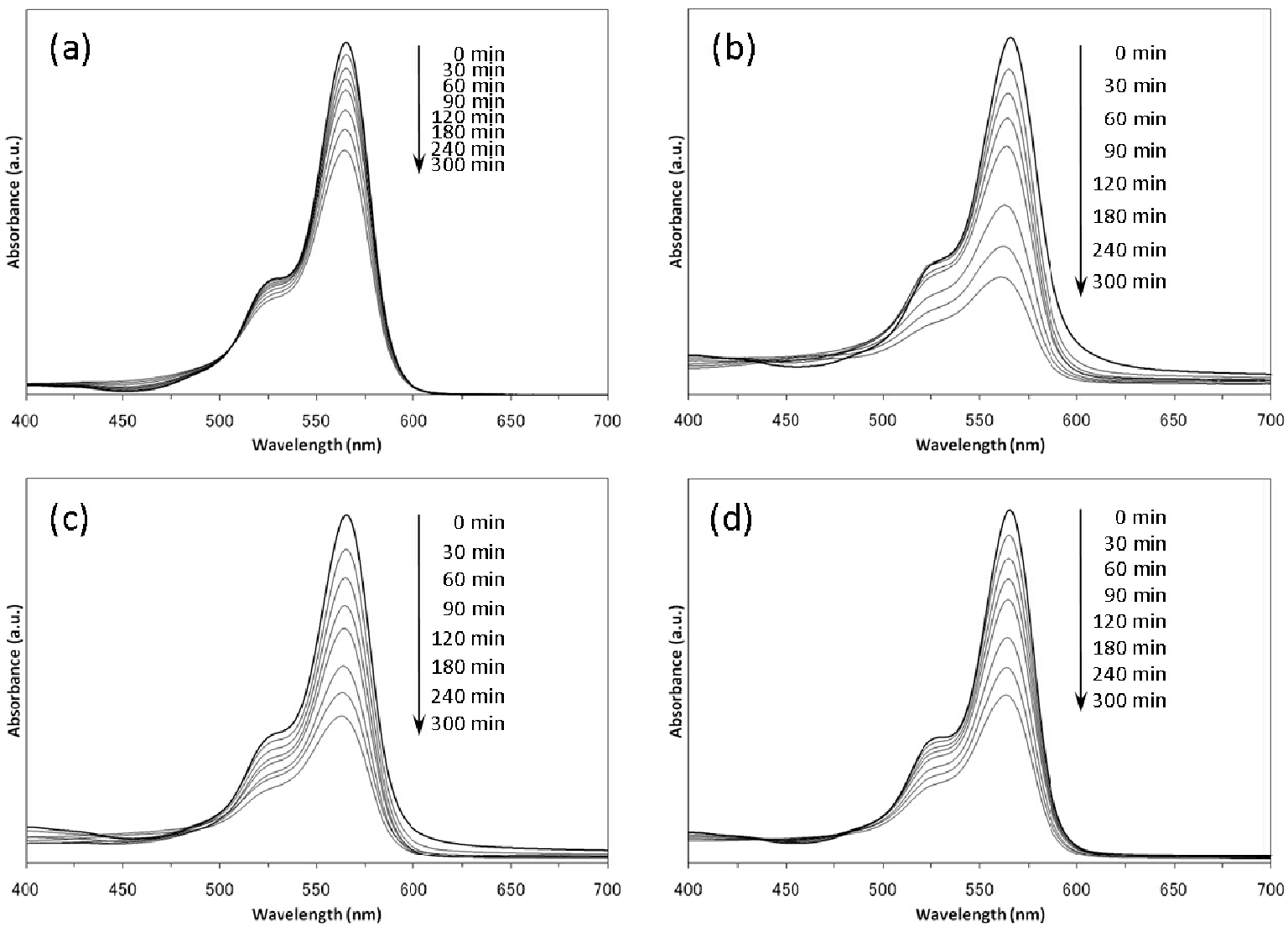

Fig. 2 Changes in UV-Vis absorption spectra during UV irradiation of (a) SRB without LDH, (b) SRB with $\mathrm{Zn}_{2}-\mathrm{Al}$ $\mathrm{LDH}$ dispersed particles, (c) SRB with $\mathrm{Zn}_{3}-\mathrm{Al} \mathrm{LDH}$, and (d) SRB with $\mathrm{Zn}_{4}-\mathrm{Al} \mathrm{LDH}$.

SRB were slightly shifted toward shorter wavelengths (blue shift).

We examined the wavelength shift of SRB without $\mathrm{LDH}$ and with $\mathrm{Zn}_{2}-\mathrm{Al} \mathrm{LDH}$ as a function of irradiation time (Fig. 3). The blue shift in SRB with $\mathrm{Zn}_{2}-\mathrm{Al} \mathrm{LDH}$ was large compared with that of SRB without LDH. This was likely caused by the photo-induced catalytic degradation of SRB by Zn-Al LDH. This hypsochromic shift indicated the occurrence of de-ethylation during the oxidation of SRB. These results were consistent with that of previous research, which was performed in a $\mathrm{TiO}_{2}$ dispersion system ${ }^{11-14}$.

We summarized the relative degradation rates of SRB without LDH and with each $\mathrm{Zn}-\mathrm{Al} \mathrm{LDH}$ under UV irradiation (Fig. 4). The degradation rates were determined from reductions in the absorbance of SRB at $565 \mathrm{~nm}$. After $300 \mathrm{~min}$ of UV irradiation, the absorbance of SRB without LDH at $565 \mathrm{~nm}$ had dropped by $30 \%$. In contrast, the absorption peaks of SRB with each $\mathrm{Zn}-\mathrm{Al} \mathrm{LDH}$ had been reduced by more than half after $300 \mathrm{~min}$ of UV irradiation. Furthermore, $\mathrm{Zn}-\mathrm{Al}$ LDH with a high charge density (e.g. $\mathrm{Zn}_{2}-\mathrm{Al} \mathrm{LDH}$ ) was more effective for continuous photo-induced degradation of SRB in aqueous solution compared with $\mathrm{Zn}-\mathrm{Al} \mathrm{LDH}$ with a low layer charge.

Therefore, Zn-Al-substituted LDH had photocatalytic activity for SRB anions in aqueous solution. $\mathrm{Zn}-\mathrm{Al} \mathrm{LDH}$ displayed performance sufficient for SRB decomposition and decolorization. Even though the

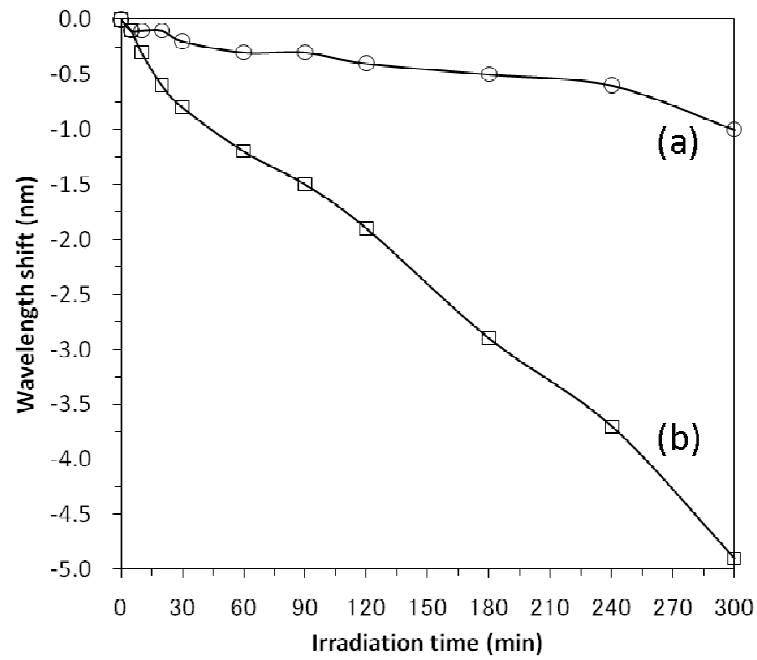

Fig. 3 Wavelength shifts of (a) SRB without LDH and (b) SRB with $\mathrm{Zn}_{2}-\mathrm{Al} \mathrm{LDH}$ as a function of UV irradiation time.

organic compounds were intercalated into $\mathrm{Zn}-\mathrm{Al} \mathrm{LDH}$ interlayers, degradation was accelerated without stabilization under UV irradiation.

\section{CONCLUSION}

Zn-Al-substituted LDH phases were successfully synthesized without any byproducts. The results of UV 
irradiation experiments indicated that $\mathrm{Zn}$-Al-substituted LDH had photocatalytic activity toward SRB in aqueous solution, and $\mathrm{Zn}-\mathrm{Al} \mathrm{LDH}$ with a high charge density was the most effective for continuous photo-induced degradation.

$\mathrm{Zn}-\mathrm{Al} \mathrm{LDH}$ has an extremely high anion adsorption capacity and relatively large reactive surfaces, and it is easily synthesized. Additionally, $\mathrm{Zn}-\mathrm{Al} \mathrm{LDH}$ is more stable than $\mathrm{ZnO}$ in aqueous solutions owing to the formation of a solid solution with Al. Therefore, Zn-Al-substituted LDH could be utilized as an efficient photocatalyst for the degradation of harmful organic anions in various environments.

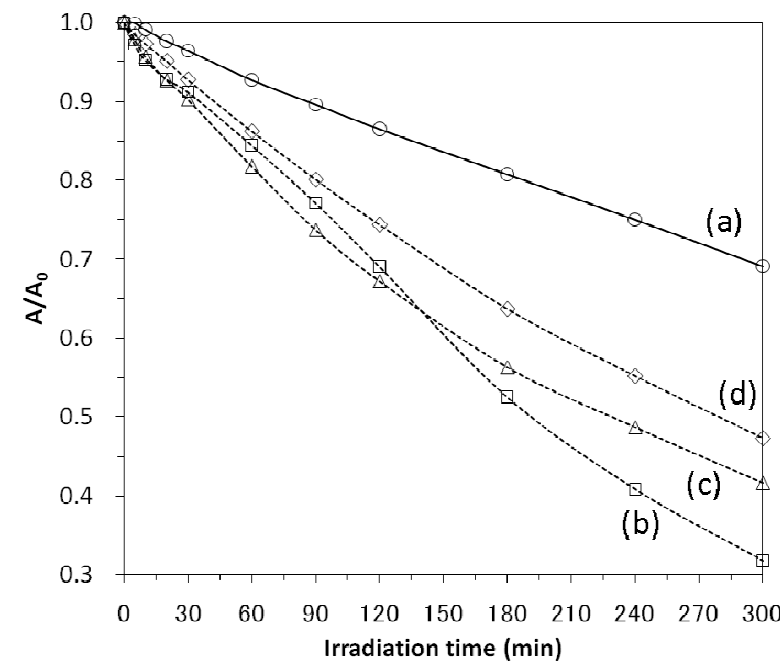

Fig. 4 Relative residual rates of (a) SRB without LDH, (b) SRB with $\mathrm{Zn}_{2}-\mathrm{Al} \mathrm{LDH}$, (c) $\mathrm{SRB}$ with $\mathrm{Zn}_{3}-\mathrm{Al}$ $\mathrm{LDH}$, and (d) SRB with $\mathrm{Zn}_{4}-\mathrm{Al} \mathrm{LDH}$ as a function of UV irradiation time.

\section{ACKNOWLEDGMENT}

The authors warmly thank Y. Yajima of the National Institute for Materials Science for the analyses of the chemical composition of Zn-Al LDH by using ICP-AES.

\section{REFERENCES}

[1] A. Fujishima, X. Zhang and D. A. Tryk, Surf. Sci. Rep., 63, 515-582 (2008).

[2] W. T. Reichle, Solid State Ionics, 22, 135-141 (1986).

[3] F. Cavani, F. Trifiro and A. Vaccari, Catal. Today, 11, 173-301 (1991).

[4] V. Rives and M. A. Ulibarri, Coord. Chem. Rev., 181, 61-120 (1999).

[5] A. Patzko, R. Kun, V. Hornok, I. Dekany, T. Engelhardt and N. Schall, Colloids Surf. A, 265, 64-72 (2005).

[6] J. S. Valente, F. Tzompantzi, J. Prince, J. G. H. Cortez and R. Gomez, Appl. Catal. B, 90, 330-338 (2009).

[7] A. Mantilla, F. Tzompantzi, J. L. Fernandez, J. A. I. D. Gongora, G. Mendoza and R. Gomez, Catal. Today, 148, 119-123 (2009).

[8] E. M. Seftel, E. Popovici, M. Mertens, K. De Witte, G. Van Tendeloo, P. Cool and E. F. Vansant, Micropor. Mesopor. Mater., 113, 296-304 (2008).

[9] K. Morimoto, K. Tamura, J. Ye and H. Yamada, Trans. Mater. Res. Soc. Jpn., 35, 813-816 (2010).

[10] F. Kooli, C. Depege, A. de Roy and J. P. Besse, Clays Clay Miner., 45, 92-98 (1997).

[11] G. Liu and J. Zhao, New J. Chem., 24, 411-417 (2000).

[12] G. Liu, X. Li and J. Zhao, Environ. Sci. Technol., 34, 3982-3990 (2000).

[13] H. Liu, W. Yang, Y. Ma and J. Yao, Appl. Catal. A, 299, 218-223 (2006).

[14] Y.-F. Fang, Y.-P. Huang, D.-F. Liu, Y. Huang, W. Guo and J. David, J. Environ. Sci., 19, 97-102 (2007). 